\title{
Detection of the Production of Klebsiella Pneumoniae Carbapenemase, New Delhi Metallo-Beta-Lactamase and Oxacillinase-48-Type Carbapenemases by Gram-Negative Bacilli in Resource-Limited Setting
}

\author{
Cecile Okalla Ebongue ${ }^{1,2 *}$ (D) Gabin Gaël Simo², Jean Pierre Nda Mefo'o'o ${ }^{1,2}$, Grace Dalle Ngondi ${ }^{2,3}$, \\ Emmanuel Roddy Mengue', Guy Pascal Ngaba ${ }^{2,4}$, Dieudonne Adiogo ${ }^{2}$
}

${ }^{1}$ Laboratory of Clinical Biology, General Hospital, Douala, Cameroon

${ }^{2}$ Department of Biological Sciences, Faculty of Medicine and Pharmaceutical Sciences, Douala, Cameroon

${ }^{3}$ Laboratory Unit, Laquintinie Hospital, Douala, Cameroon

${ }^{4}$ Laboratory Unit, Gyneco-Obstetric and Pediatric Hospital, Douala, Cameroon

Email: *cecileokalla@yahoo.fr, Gabin_s@yahoo.fr,drnda41@yahoo.fr, ngondigrace@yahoo.fr, packyroddy@yahoo.fr, pascalngaba1974@gmail.com,d_adiogo@yahoo.fr

How to cite this paper: Ebongue, C.O., Simo, G.G., Mefo'o, J.P.N., Ngondi, G.D., Mengue, E.R., Ngaba, G.P. and Adiogo, D. (2021) Detection of the Production of Klebsiella Pneumoniae Carbapenemase, New Delhi Metallo-Beta-Lactamase and Oxacillinase-48-Type Carbapenemases by Gram-Negative Bacilli in Resource-Limited Setting. Advances in Microbiology, 11, 579-590.

https://doi.org/10.4236/aim.2021.1110042

Received: September 16, 2021

Accepted: October 23, 2021

Published: October 26, 2021

\begin{abstract}
Background: The increasing resistance of bacteria to various antibiotics is a worldwide public health issue. Carbapenems that have elicited great hope in treating infections caused by multidrug-resistant germs have seen their efficacy narrowed over time with the emergence of other novel resistance mechanisms, notably the production of Carbapenemases. Methods: A prospective cross-sectional study was conducted from May 2017 to May 2018 in Douala (Cameroon) to detect carbapenemase-producing Gram-negative bacilli. Isolated strains were identified using the Vitek $2^{\mathrm{TM}}$ system. Antimicrobial susceptibility testing was performed using the Kirby-Bauer disk diffusion method on agar plates with 20 selected commercially available antibiotic discs. The bacterial strains were tested for the production of three Carbapenemases (OXA-48, NDM, KPC), using an immuno-chromatographic technique, with the "RESIST-3 O.K.N. K-SeT" rapid detection kit. Results: During the study period, 1687 strains of Gram-negative bacilli were isolated in selected laboratories with a total of 200 multi-resistant strains identified (11.9\%). Among the multi-resistant strains, E. coli was the species most represented in Enterobacteriaceae (27.5\%) followed by $K$. pneumoniae
\end{abstract}


Copyright $\odot 2021$ by author(s) and Scientific Research Publishing Inc. This work is licensed under the Creative Commons Attribution International License (CC BY 4.0).

http://creativecommons.org/licenses/by/4.0/
(15.5\%) and the non-fermenting Gram-negative bacilli were predominantly P. aeruginosa (20.5\%). These strains mainly came from urine and pus, i.e. $41 \%$ and $32 \%$ respectively. Thirty-two (16\%) strains produced one of the Carbapenemases with a higher frequency at the General Hospital (84\%). NDM-type carbapenemase was the most frequently identified (8.5\%), OXA-48 type 7.5\%, and no KPC production was observed. Among the Enterobacteriaceae $22.9 \%$ produced Carbapenemases and only $5.1 \%$ of the non-fermenting bacilli produced these enzymes. The isolates strains were completely resistant to all antibiotics except Amikacin and Fosfomycin. The strains producing the NDM-type carbapenemase showed higher rates of resistance to almost all of the antibiotics tested. Conclusion: Multidrug-resistant strains are experiencing an increase in evolution. The apparition of strains producing Carbapenemases prominently, the NDM and OXA-48 favor this increase. The activities of antibiotics with high efficacies on these strains are low.

\section{Keywords}

Carbapenemases, Gram-Negative Bacilli, Multidrug-Resistance, Cameroon

\section{Introduction}

The resistance of bacteria to antibiotics poses a significant public health problem globally, particularly in countries with limited resources [1]. The increased resistance is of particular concern in gram-negative bacilli such as Pseudomonas aeruginosa, Acinetobacter baumannii and Enterobacteriaceae, the latter being the most found in humans [2] [3]. To treat infections caused by bacteria that show multiple resistances to antibiotics, Carbapenems are given as a last resort [4]. Their excellent anti-bacterial activity is mainly linked to the rapidity of their trans-membrane penetration through the external wall of gram-negative bacilli and their stability concerning most natural or acquired $\beta$-lactamases including cephalosporinases and extended-spectrum $\beta$-lactamases [5]. Unfortunately, bacteria have been able to adapt and have developed resistance mechanisms for these Carbapenems. This resistance is linked either to the association of the overexpression of extended-spectrum $\beta$-lactamases with the efflux pump and impermeability, or to the expression of $\beta$-lactamases hydrolyzing Carbapenems, known as Carbapenemases [6].

According to Ambler's classification, Carbapenemases belong to three of the four classes of $\beta$-lactamases (A, B, C and D), the most frequent being of type Klebsiella pneumoniae Carbapenemase (KPC, class A), New Delhi Metallo-beta-lactamase (NDM, class B) and Oxacillinases of type OXA-48 (class D) [5] [7]. The other danger of carbapenemase-producing strains is that they are resistant to all the most effective antibiotics and being colonized by them is an independent risk factor for mortality [8]. The therapeutic limits resulting from the 
resistance of these microorganisms to Carbapenems and other antibiotics underline the importance of preventing, limiting and controlling their spread. The prerequisite for taking these measurements is their knowledge, then their detection using techniques that vary from the most expensive such as mass spectrometry and molecular biology to the more accessible such as rapid diagnostic tests [9]. This study aimed to investigate the production of Carbapenemases by Gram-negative bacilli isolated in the city of Douala using an accessible technique.

\section{Methods}

\subsection{Design and Location of the Study}

This was a descriptive cross-sectional study conducted from May 2017 to May 2018 (12 months) on the detection of carbapenemase production by Gram-negative bacilli. The strains were collected in several hospitals in the city of Douala, in particular the General Hospital, the Laquintinie Hospital, the Gyneco-Obstetric and Pediatric Hospital, the Military Hospital and at the Bonassama District Hospital. Strain analysis was carried out in the clinical biology laboratory of the Douala General Hospital (DGH). All strains of Gram-negative bacilli isolated from clinical specimen in one of the five selected hospitals and during the study period were included in the study.

\subsection{Samples Collection}

Samples collected from patients in hospitals were urine, blood, pus and other fluids from puncture like ascites and synovial liquid. Strains from positive culture were collected with a sterile swab in their primary culture medium (Eosin Methylene Blue, Cystine Lactose Electrolyte Deficient, Mac Conkey, Salmonella Shigella), then transported in screw tubes containing regular broth. These tubes were placed in a cooler, transported quickly to the place of analysis where the strains were re-isolated on Eosin Methylene Blue culture medium and incubated at $37^{\circ} \mathrm{C}$ for 18 to 24 hours.

\subsection{Identification and Susceptibility to Antibiotics}

The strains were identified by the automatic colorimetric method using Vitek $2^{\mathrm{TM}}$ (Biomérieux). An antibiogram was carried out by the diffusion method in Mueller Hinton agar with a range consisting of a panel of 20 standard antibiotics, namely Amoxicillin + Clavulanic acid $(30 \mu \mathrm{g})$; Ticarcillin + Clavulanic acid $(85 \mu \mathrm{g})$; Piperacillin + Tazobactam $(85 \mu \mathrm{g})$; Tobramycin $(10 \mu \mathrm{g})$; Levofloxacin $(5 \mu \mathrm{g})$; Norfloxacin $(5 \mu \mathrm{g})$; Ceftriaxone $(30 \mu \mathrm{g})$; Cefixime $(5 \mu \mathrm{g})$; Cefepime $(30 \mu \mathrm{g})$; Ceftazidime $(30 \mu \mathrm{g})$; Meropenem $(10 \mu \mathrm{g})$; Ertapenem $(10 \mu \mathrm{g})$; Imipenem $(10 \mu \mathrm{g})$; Amikacin $(30 \mu \mathrm{g})$; Gentamicin $(15 \mu \mathrm{g})$; Ofloxacin $(5 \mu \mathrm{g})$; Ciprofloxacin $(5 \mu \mathrm{g})$; Cefotaxime $(30 \mu \mathrm{g})$; Fosfomycin $(50 \mu \mathrm{g})$; Nalidixic acid $(30 \mu \mathrm{g})$. The European Committee on Antimicrobial Susceptibility Testing (EUCAST v 6.0) standards used as interpretive criteria for antimicrobial susceptibility testing (https://www.eucast.org/). 


\subsection{Detection of Carbapenemases}

The search for carbapenemase was carried out on Multi-Drug-Resistant (MDR) strains; that is resistant to at least three classes of antibiotics. The test for the production of the Carbapenemases was carried out from a bacterial suspension by the rapid immuno-chromatographic technique using the "RESIST-3 O.K.N.

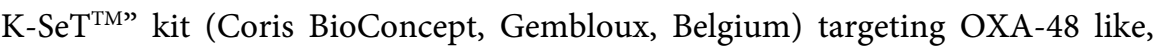
KPC, and NDM type Carbapenemases. The principle of this test is based on the detection of a colored indicator after 15 minutes indicating the presence of carbapenemase, and the result obtained was interpreted according to the manufacturer's recommendations (Figure 1).

\subsection{Statistical Analysis}

Microsoft Office Excel 2010 software was used to record the data and calculate the frequencies. The qualitative variables were represented in frequency and we used the $\mathrm{Khi}^{2}$ test to compare the variables. The difference was considered statistically significant for a p-value less than 0.05 .

\section{Results}

\subsection{Isolated Strains}

During the study period, 1687 strains of Gram-negative bacilli were isolated from 5252 specimens received in the selected laboratories, mainly for urine analysis (60\%) and blood cultures (17\%); Enterobacteriaceae were the most represented group with $E$. coli as the most frequent species (30\%) followed by $K$. pneumoniae (23\%). Pseudomonas aeruginosa was the most common species in non-fermentative Gram-negative bacilli with $11 \%$ of cases.

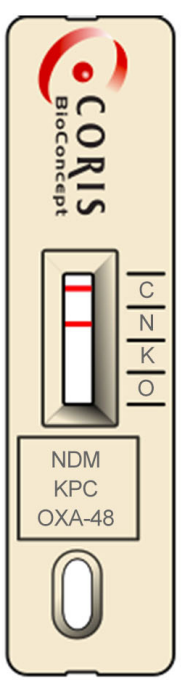

NDM

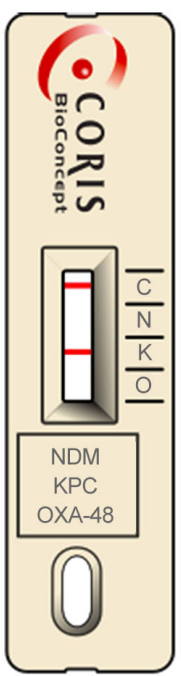

KPC

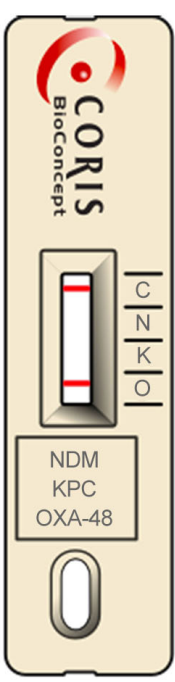

OXA-48

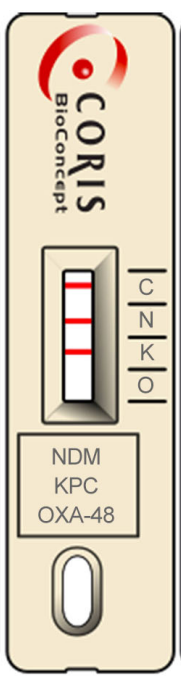

$\mathrm{NDM}+\mathrm{KPC}$

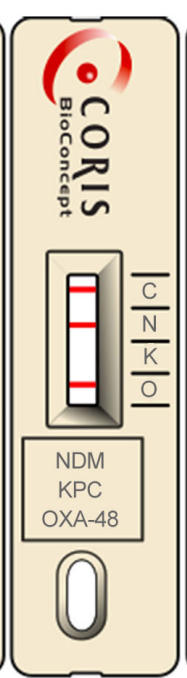

$\mathrm{NDM}+\mathrm{OXA}-48$

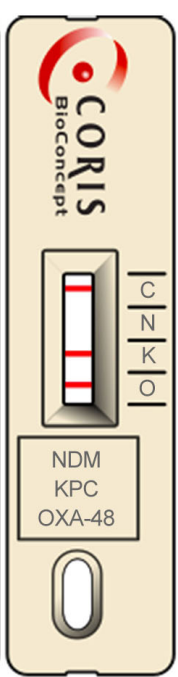

$\mathrm{KPC}+\mathrm{OXA}-48 \quad \mathrm{NDM}+\mathrm{KPC}+\mathrm{OXA}-48$

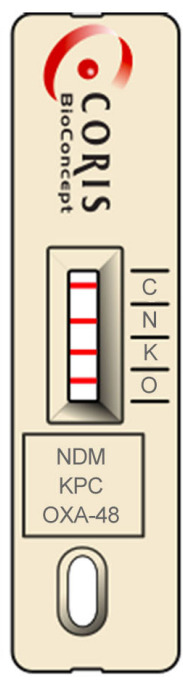

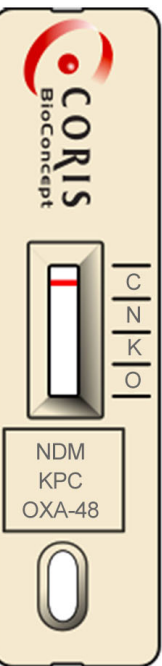

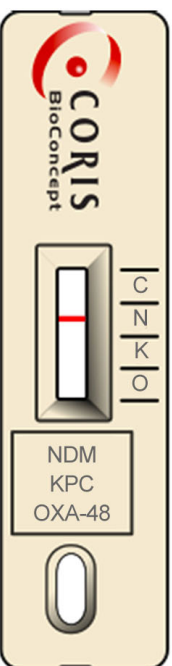

Negative

Invalid

Figure 1. Reading and interpretation of the results. 


\subsection{Multi-Resistant Strains}

A total of 200 multi-resistant strains were identified, i.e., a relative frequency of $11.9 \%$. The frequency of these strains was higher at General Hospital and Laquintinie Hospital with $85 \%$ and $12 \%$ respectively (Table 1). Among the multi-resistant strains, E. coli was the species most represented in Enterobacteriaceae $(27.5 \%)$ followed by $K$. pneumoniae $(15.5 \%)$ and the non-fermenting Gram-negative bacilli were predominantly $P$. aeruginosa (20.5\%) followed by $A$. baumannii (15.5\%). These strains mainly came from urine and pus, i.e., $41 \%$ and $32 \%$, respectively.

\subsection{Carbapenemases Producing Strains}

Thirty-two (32) or 16\% of the strains produced one of the Carbapenemases with a higher frequency at the General Hospital (84\%). NDM-type carbapenemase was the most frequently identified (8.5\%), OXA-48 type $7.5 \%$, and no KPC production was observed. The strains producing Carbapenemases came mainly from urine specimens (41\%) followed by pus with $31.5 \%$ (Table 2). Among the Enterobacteriaceae $22.9 \%$ produced Carbapenemases and only $5.1 \%$ of the non-fermenting bacilli produced these enzymes. The frequency of carbapenemase production was $25.4 \%$ for E. coli, $19.3 \%$ for $K$. pneumoniae and $6.4 \%$ for Acinetobacter baumannii (Table 2, Table 3).

Table 1. Distribution of multi-resistant strains according to the species.

\begin{tabular}{|c|c|c|c|c|c|c|}
\hline Group & Genera & Species & $\begin{array}{c}\text { DGH } \\
\mathrm{N}=170\end{array}$ & $\begin{array}{c}\text { LHD } \\
\mathrm{N}=24\end{array}$ & $\begin{array}{c}\text { Others } \\
\mathrm{N}=6\end{array}$ & $\begin{array}{l}\text { Total } \\
\text { n (\%) }\end{array}$ \\
\hline \multirow{10}{*}{ Enterobacteriaceae } & Escherichia & E. coli & 48 & 6 & 1 & $55(27.5)$ \\
\hline & Klebsiella & $K$. pneumoniae & 27 & 3 & 1 & $31(15.5)$ \\
\hline & & C. freundii & 1 & 0 & 0 & $1(0.5)$ \\
\hline & Citrobacter & C. koseri & 3 & 0 & 0 & $3(1.5)$ \\
\hline & Enterobacter & E. cloacae & 7 & 2 & 1 & $10(5)$ \\
\hline & Proteus & P. mirabilis & 12 & 2 & 0 & $14(7)$ \\
\hline & Morganella & M. morganii & 4 & 0 & 0 & $4(2)$ \\
\hline & Providencia & P. stuartii & 2 & 0 & 0 & $2(1)$ \\
\hline & Serratia & S. marcescens & 1 & 0 & 0 & $1(0.5)$ \\
\hline & Raoutella & $R$. ornithinolytica & 0 & 0 & 1 & $1(0.5)$ \\
\hline \multirow{6}{*}{ NFGNB } & \multirow{3}{*}{ Pseudomonas } & $P$. aeruginosa & 32 & 7 & 2 & $41(20.5)$ \\
\hline & & P. fluorescens & 2 & 1 & 0 & $3(1.5)$ \\
\hline & & $P$. putida & 1 & 0 & 0 & $1(0.5)$ \\
\hline & \multirow{2}{*}{ Acinetobacter } & A. baumannii & 28 & 3 & 0 & $31(15.5)$ \\
\hline & & A. Iwoffii & 1 & 0 & 0 & $1(0.5)$ \\
\hline & Achromobacter & A. anthropi & 1 & 0 & 0 & $1(0.5)$ \\
\hline
\end{tabular}

Khi- 2 of Pearson $=158.696$; dd $=60$; p-value $=0.000^{*}$; DGH $=$ Douala General Hospital $/$ LHD $=$ Laquintinie Hospital Douala; Others: Douala Gyneco-Obstetric and Pediatric Hospital, Bonassama District Hospital, Douala Military Hospital; NFGNB = Non-fermenting Gram-negative bacilli. 
Table 2. Origin of strains producing carbapenemases.

\begin{tabular}{|c|c|c|c|c|c|c|}
\hline \multirow{2}{*}{\multicolumn{2}{|c|}{ Characteristics }} & \multicolumn{4}{|c|}{ Carbapenemases production } & \multirow{2}{*}{$\begin{array}{l}\text { Total } \\
\text { n (\%) }\end{array}$} \\
\hline & & NDM & OXA-48 & KPC & None & \\
\hline \multirow{6}{*}{ Sample } & Urine & 6 & 10 & 0 & 66 & $82(41)$ \\
\hline & Pus & 3 & 3 & 0 & 57 & $63(31.5)$ \\
\hline & Urinary probe & 3 & 1 & 0 & 20 & $24(12)$ \\
\hline & Blood culture & 3 & 1 & 0 & 11 & $15(7.5)$ \\
\hline & Catheter & 1 & 0 & 0 & 9 & $10(5)$ \\
\hline & Puncture liquid & 1 & 0 & 0 & 5 & $6(3)$ \\
\hline \multirow{5}{*}{ Health facility } & DGH & 15 & 14 & 0 & 139 & $168(84)$ \\
\hline & LHD & 1 & 1 & 0 & 24 & $26(13)$ \\
\hline & DGOPH & 1 & 0 & 0 & 2 & $3(1.5)$ \\
\hline & $\mathrm{DMH}$ & 0 & 0 & 0 & 1 & $1(0.5)$ \\
\hline & $\mathrm{BDH}$ & 0 & 0 & 0 & 2 & $2(1)$ \\
\hline \multicolumn{2}{|c|}{ Total n (\%) } & $17(8.5)$ & $15(7.5)$ & $0(0)$ & $168(84)$ & $200(100)$ \\
\hline
\end{tabular}

Khi-2 of Pearson $=9.745 ; \mathrm{ddl}=10 ; \mathrm{p}$-value $=0.463 . \mathrm{DGH}=$ Douala General Hospital $/ \mathrm{LHD}=$ Laquintinie Hospital Douala/DGOPH $=$ Douala Gyneco-Obstetric and Pediatric Hospital/BDH $=$ Bonassama District Hospital/DMH = Douala Military Hospital.

Table 3. Distribution of the types of carbapenemase identified according to the species.

\begin{tabular}{|c|c|c|c|c|c|c|}
\hline \multirow{2}{*}{ Group } & \multirow{2}{*}{ Specie } & \multirow{2}{*}{$\begin{array}{c}\text { Frequency } \\
\text { n }\end{array}$} & \multirow{2}{*}{$\begin{array}{c}\text { Carbapenemase } \\
\text { production } \\
\text { n (\%) }\end{array}$} & \multicolumn{3}{|c|}{ Type of Carbapenemase } \\
\hline & & & & NDM & OXA-48 & $\mathrm{KPC}$ \\
\hline \multirow{10}{*}{ Enterobacteriaceae } & E. coli & 55 & $14(25.4)$ & 4 & 10 & 0 \\
\hline & $K \cdot$ pneumoniae & 31 & $6(19.3)$ & 3 & 3 & 0 \\
\hline & P. mirabilis & 14 & $1(7.1)$ & 1 & 0 & 0 \\
\hline & C. freundii & 1 & $1(100)$ & 1 & 0 & 0 \\
\hline & C. koseri & 3 & $1(33.3)$ & 1 & 0 & 0 \\
\hline & E. cloacae & 9 & $1(11.1)$ & 0 & 1 & 0 \\
\hline & M. morganii & 4 & $1(25)$ & 1 & 0 & 0 \\
\hline & P. stuartii & 2 & $1(50)$ & 1 & 0 & 0 \\
\hline & S. marcescens & 2 & $1(50)$ & 1 & 0 & 0 \\
\hline & R. ornithinolytica & 1 & $1(100)$ & 1 & 0 & 0 \\
\hline \multicolumn{2}{|c|}{ Total 1} & 122 & $28(22.9)$ & 14 & 14 & 0 \\
\hline \multirow{6}{*}{ NFGNB } & $P$. aeruginosa & 41 & $1(2.4)$ & 0 & 1 & 0 \\
\hline & P. fluorescens & 3 & $0(0)$ & 0 & 0 & 0 \\
\hline & P. putida & 1 & $0(0)$ & 0 & 0 & 0 \\
\hline & A. baumannii & 31 & $2(6.4)$ & 2 & 0 & 0 \\
\hline & A. Iwoffii & 1 & $0(0)$ & 0 & 0 & 0 \\
\hline & A. anthropi & 1 & $1(100)$ & 1 & 0 & 0 \\
\hline \multicolumn{2}{|c|}{ Total 2} & 78 & $4(5.1)$ & 3 & 1 & 0 \\
\hline \multicolumn{2}{|c|}{ Total $1+2$} & 200 & $32(16)$ & 17 & 15 & 0 \\
\hline
\end{tabular}

Khi-2 of Pearson $=51.982 ; \mathrm{ddl}=30 ; \mathrm{p}$-value $=0.008 ; \mathrm{NFGNB}=$ Non-fermenting Gram-negative bacilli. 


\subsection{Susceptibility to Antibiotics}

Both carbapenemase-producing and non-carbapenemase-producing strains were totally resistant to all antibiotics except Amikacin and Fosfomycin; these molecules were also more active for strains producing OXA-48 than those producing NDM (Table 4).

The majority of strains (75\%) resistant to at least one of the Carbapenem antibiotic (Imipenem, Meropenem or Ertapenem) produced none of the three types of Carbapenemases. The strains producing the NDM-type carbapenemase showed higher resistance rates to almost all of the antibiotics tested (Table 4).

\subsection{Carbapenem Resistance Phenotypes}

Among Carbapenems, Ertapenem was less active than Imipenem and Meropenem. The carbapenemase-producing strains exhibited very high Minimal Inhibitory Concentrations (MIC) for the majority of them (>16 for Imipenem and Meropenem, and 8 for Ertapenem). A strain producing NDM carbapenemase and one strain producing OXA-48 had MIC of a phenotype sensitive to Imipenem and Meropenem, respectively (Table 5).

Table 4. Antibiotic resistance according to the expression of the NDM and OXA-48 type carbapenemases.

\begin{tabular}{|c|c|c|c|c|c|c|}
\hline \multirow[b]{2}{*}{ Antibiotic } & \multicolumn{3}{|c|}{ Resistance rate $\%$} & \multirow[b]{2}{*}{$\mathrm{Khi}^{-2}$} & \multirow[b]{2}{*}{ ddl } & \multirow[b]{2}{*}{$\mathrm{p}$-value } \\
\hline & $\begin{array}{l}\text { OXA-48 } \\
\mathrm{N}=15\end{array}$ & $\begin{array}{c}\mathrm{NDM} \\
\mathrm{N}=17\end{array}$ & $\begin{array}{l}\text { Multi-resistant } \\
\text { strains }\end{array}$ & & & \\
\hline $\mathrm{AMO} / \mathrm{TIC}$ & 100 & 100 & 100 & 0.191 & 2 & 0.909 \\
\hline PIT & 93.3 & 100 & 93.5 & 5.692 & 4 & 0.223 \\
\hline $\mathrm{CFM} / \mathrm{CFO}$ & 100 & 100 & 100 & 0.385 & 2 & 0.825 \\
\hline CAZ/CTX & 100 & 100 & 99 & 1.603 & 4 & 0.808 \\
\hline Cefepime & 100 & 100 & 98.5 & 2.088 & 4 & 0.720 \\
\hline Imipenem & 100 & 94.1 & 80 & 7.245 & 4 & 0.123 \\
\hline Meropenem & 93.3 & 100 & 76 & 12.028 & 4 & $0.017^{*}$ \\
\hline Ertapenem & 100 & 100 & 89 & 7.348 & 4 & 0.119 \\
\hline Amikacin & 46.7 & 94.1 & 61.5 & 14.727 & 4 & $0.005^{*}$ \\
\hline Gentamycin & 100 & 100 & 97.5 & 1.382 & 2 & 0.501 \\
\hline Tobramycin & 86.7 & 100 & 92 & 15.219 & 6 & $0.019^{*}$ \\
\hline Nalidixic acid & 100 & 100 & 99.5 & 11 & 4 & $0.027^{*}$ \\
\hline Ciprofloxacin & 100 & 100 & 97.5 & 11.746 & 4 & $0.019^{*}$ \\
\hline LEV/NOR & 100 & 100 & 100 & I & I & I \\
\hline Ofloxacin & 100 & 100 & 99.5 & 0.580 & 4 & 0.965 \\
\hline Fosfomycin & 40 & 76.5 & 55 & 5.461 & 2 & 0.065 \\
\hline
\end{tabular}

AMO = Amoxicillin + Clavulanic acid/TIC $=$ Ticarcillin + Clavulanic acid $/ \mathrm{PIT}=$ Piperacillin + Tazobac$\operatorname{tam} / \mathrm{CFM}=$ Cefixime $/ \mathrm{CFO}=$ Cefotaxime $/ \mathrm{CAZ}=$ Ceftazidime $/ \mathrm{CTX}=$ Ceftriaxone $/ \mathrm{LEV}=$ Levofloxacin $/ \mathrm{NOR}$

$=$ Norfloxacin 
Table 5. Phenotypes and variability of MICs of carbapenems in Gram-negative bacilli.

\begin{tabular}{|c|c|c|c|c|c|}
\hline \multirow[b]{2}{*}{ Carbapenem } & \multirow[b]{2}{*}{ Phenotype } & \multirow[b]{2}{*}{ MIC (mg/l) } & \multicolumn{3}{|c|}{ Carbapenemase production } \\
\hline & & & $\begin{array}{c}\text { OXA-48 + } \\
(\mathrm{N}=15)\end{array}$ & $\begin{array}{l}\mathrm{NDM}+ \\
(\mathrm{N}=17)\end{array}$ & $\begin{array}{l}\text { Negative } \\
(\mathrm{N}=168)\end{array}$ \\
\hline \multirow{5}{*}{ Imipenem } & S & $\leq 2$ & 0 & 1 & 39 \\
\hline & I & $2<\mathrm{MIC}>4$ & 1 & 0 & 8 \\
\hline & $\mathrm{R}$ & $4 \leq \mathrm{MIC}>8$ & 1 & 1 & 12 \\
\hline & $\mathrm{R}$ & $8 \leq \mathrm{MIC} \geq 16$ & 8 & 4 & 61 \\
\hline & $\mathrm{R}$ & $>16$ & 5 & 11 & 48 \\
\hline \multirow{5}{*}{ Meropenem } & S & $\leq 2$ & 1 & 0 & 47 \\
\hline & I & $2<\mathrm{MIC}>4$ & 2 & 0 & 10 \\
\hline & I & $4 \leq \mathrm{MIC}>8$ & 3 & 0 & 11 \\
\hline & $\mathrm{R}$ & $8 \leq \mathrm{MIC} \geq 16$ & 4 & 7 & 55 \\
\hline & $\mathrm{R}$ & $>16$ & 5 & 10 & 45 \\
\hline \multirow{5}{*}{ Ertapenem } & S & $\leq 0.5$ & 0 & 0 & 22 \\
\hline & $\mathrm{R}$ & $0.5<\mathrm{MIC}>1$ & 4 & 0 & 18 \\
\hline & $\mathrm{R}$ & $1 \leq \mathrm{MIC}>4$ & 3 & 3 & 17 \\
\hline & $\mathrm{R}$ & $4 \leq \mathrm{MIC} \geq 8$ & 4 & 5 & 54 \\
\hline & $\mathrm{R}$ & $>8$ & 3 & 6 & 57 \\
\hline
\end{tabular}

$\mathrm{S}=$ Sensitive strains at standard dosage; $\mathrm{R}=$ Resistant strains; $\mathrm{I}=$ Sensitive strains at high dosage.

\section{Discussion}

Multi-resistant strains were isolated in the five selected hospitals with a variable frequency due to the type of attendance and the level of activity of the health facility. As the Douala General Hospital and Laquintinie Hospital are referral hospitals, complex cases are transferred to them for better management. The multidrug-resistant strains came mostly from urine and pus samples, a result similar to those obtained in other national studies in 2018 [10]. The pathologies caused by bacteria resistant to Carbapenems are mostly urinary tract infections, as well as sepsis and soft tissue infections [11]. The prevalence of carbapenemase production was high in our study (16\%) compared to the work of Betbeu et al. in Cameroon in 2015 (11\%) and Yusuf et al. in Nigeria in 2011 (13.3\%) on Klebsiella spp strains [12] [13]. This observed increase could be justified by the larger target population including Enterobacteriaceae and non-fermenting Gram-negative bacilli and also by the ever-increasing evolution of the resistance of bacteria to antibiotics over time [14]. The NDM-type carbapenemase of the Metallo-beta-lactamase group was the most common. The study of Vaux et al. in 2011 showed a higher frequency of the OXA- 48 type followed by the KPC type, which may be justified by differences in the geographical distribution of Carbapenemases; Cameroon is an epidemiologically sporadic zone [15] [16]. The identified NDM and OXA-48 type Carbapenemases were more frequent in En- 
terobacteriaceae and mainly in $E$. coli and $K$. pneumoniae respectively. In France, Vaux et al. had shown a higher frequency in $K$. pneumoniae, as did Yusuf et al. in Nigeria [13] [15]. Currently the production of NDM in Enterobacteriaceae has been reported almost everywhere globally, especially in Asia, Australia, America and Europe, with the Indian subcontinent as the main reservoir [17]. NDM-4 $\beta$-Lactamase showing increased carbapenemase activity compared to NDM-1 has been described in a hospitalized patient in India; Dortet et al. showed that this variant was also present in Africa, isolated in particular from a patient coming from Douala, carrying $E$. coli strains expressing two NDM variants [18]. We did not identify any strains producing KPCs in the geographic area of this study, although they are currently the most clinically important in the world [19]. Initially described in the United States and presently distributed worldwide, this enzyme is most often found in $K$. pneumoniae and Enterobacter spp, and rare in $P$. aeruginosa and other Enterobacteriaceae [2] [19]. The most common Carbapenemases found in $P$. aeruginosa are mainly Metallo-beta-lactamases of the VIM and IMP type; in $A$. baumanii types NDM, IMP, VIM and OXA-23, 40 and 58 which are specific to it, but not OXA 48 [20]. OXA-48-producing bacteria, often the source of epidemics of healthcare-associated infections, have been widely reported in Turkey, followed by countries in North Africa, the Middle East and India [21]. The carbapenem-resistant strains isolated in this study and not producing NDM, OXA-48 or KPC may produce Carbapenemases not sought here, or have developed other resistance mechanisms [22]. These isolates are often associated with a decrease in external permeability, which is widespread in species of Enterobacteriaceae that naturally produce a cephalosporinase such as Enterobacter spp [2]. The sensitivity profile showed good activity of Fosfomycin and Amikacin on multi-resistant strains and significant activity on strains producing OXA-48 Carbapenemases; also reported by Harchay et al. in 2016 on MDR strains and by Ebongue et al. in 2018 on Enterobacteriaceae producing Extended Spectrum Beta-lactamase (ESBL) in Douala [10] [23]. The good activity of these antibiotics on these strains could be attributed to the low use of these molecules in our environment.

This study reveals a strong resistance of the strains to Imipenem and other Carbapenems with MICs mostly greater than $4 \mu \mathrm{g} / \mathrm{ml}$. This could be attributed to an increasing evolution of antibiotic resistance like described in some European countries [18] [24].

Two strains of phenotype sensitive to Imipenem and Meropenem producing NDM and OXA-48 respectively have been identified; the use of these molecules in these cases can lead to treatment failures.

The rapid techniques making it possible to detect the activity of Carbapenemases (hydrolysis in Enterobacteriaceae, $P$. aeruginosa and A. baumanii) but not the resistance genes are very sensitive and specific with results available quickly, unlike costly molecular techniques [9]. In a study carried out in Turkey on isolates of $K$. pneumoniae, the results obtained by the RESIST-3 OKN K-SeT im- 
muno-chromatographic method were identical to those obtained by PCR targeting the carbapenemase genes $b l a_{\mathrm{KPC}}, b l a_{\mathrm{NDM}}$ and/or $b l a_{\mathrm{OXA}-48}$ with $100 \%$ concordance [25]. Han et al. demonstrated the good performances of rapid immunochromatographic tests on clinical isolates, in comparison with molecular techniques (sensitivity greater than $99.4 \%$ according to the manufacturer and specificity of $100 \%$ for all the tests used in their study) [26].

\section{Limitation}

We did not have the opportunity to confirm the expression of carbapenemase genes by PCR and DNA sequencing techniques.

\section{Conclusion}

This study on the fast detection of Carbapenemases demonstrated the presence of Gram-negative bacilli producing Carbapenemases, particularly types NDM-1 and OXA-48 in the city of Douala. It is essential to identify these layers to prevent their diffusion, the emergence of which could be linked to mutations to be explored by molecular techniques.

\section{Acknowledgements}

We express our gratitude to Mr. Michel Lambot and to the staff of all the Laboratories concerned for their support and cooperation during this study.

\section{Availability of Data}

All data supporting these findings can be found in the bacteriological Unit of the Laboratory of Clinical Biology of the DGH.

\section{Authors' Contributions}

COE and DA coordinated the study, COE, GS and JPNM drafted the manuscript, GS, ERM, GPN and GDN collected data and participated in its design, COE, GS and ERM performed the statistical analysis. All authors read and approved the final manuscript.

\section{Ethics}

The study was conducted following ethics directives related to research in Cameroon. We obtained the research authorizations of the Directors of the concerned hospitals, and ethical clearance from the Institutional Ethics Committee of Research for Human Health of the University of Douala $\left(\mathrm{N}^{\circ}\right.$ 1405/UD/FMSP), and the approval of the Douala General Hospital institutional review board.

\section{Conflicts of Interest}

The authors declare no conflicts of interest regarding the publication of this paper. 


\section{References}

[1] World Health Organization (2019) The 2019 WHO AWaRe Classification of Antibiotics for Evaluation and Monitoring of Use. Geneva.

[2] Nordmann, P. (2014) Carbapenemase-Producing Enterobacteriaceae: Overview of a Major Public Health Challenge. Médecine et Maladies Infectieuses, 44, 51-56. https://doi.org/10.1016/j.medmal.2013.11.007

[3] Tamma, P.D. and Simner, P.J. (2018) Phenotypic Detection of Carbapenemase-Producing Organisms from Clinical Isolates. Journal of Clinical Microbiology, 56, e01140.

[4] Durrmeyer, X. and Cohen, R. (2010) Utilisation des carbapénèmes en pédiatrie. Archives de pédiatrie, 17, S163-S170. https://doi.org/10.1016/S0929-693X(10)70919-2

[5] Nordmann, P. and Carrer, A. (2010) Les carbapénèmases des entérobactéries. Archives de Pédiatrie, 17, S154-S162. https://doi.org/10.1016/S0929-693X(10)70918-0

[6] Nordmann, P., Dortet, L. and Poirel, L. (2012) Carbapenem Resistance in Enterobacteriaceae: Here Is the Storm! Trends in Molecular Medicine, 18, 263-272. https://doi.org/10.1016/j.molmed.2012.03.003

[7] Raheel, A., Azab, H., Hessam, W., Abbadi, S. and Ezzat, A. (2020) Detection of Carbapenemase Enzymes and Genes among Carbapenem-Resistant Enterobacteriaceae Isolates in Suez Canal University Hospitals in Ismailia, Egypt. Microbes and Infectious Diseases, 1, 24-33. https://doi.org/10.21608/mid.2020.25702.1007

[8] Landelle, C., Dautzenberg, M., Wekesa, A., Gniadkowski, M., Antoniadou, A., Giamarellou, H., et al. (2015) The Association between Colonization with Carbapenemase-Producing Enterobacteriaceae and Overall ICU Mortality. Critical Care Medicine, 43, 1170-1177. https://doi.org/10.1097/CCM.0000000000001028

[9] Nordmann, P., Poirel, L. and Dortet, L. (2012) Rapid Detection of Carbapenemase-Producing Enterobacteriaceae. Emerging Infectious Diseases, 18, 1503-1507. https://doi.org/10.3201/eid1809.120355

[10] Ebongue, C.O., Mengue, R.N., Temfack, E., Mengue, E.R. and Adiogo, D. (2018) Phenotypic Detection of Extended Spectrum $\beta$-Lactamase and AmpC Producing Enterobacteriaceae Isolated in a General Hospital. Journal of Microbiology and Infectious Diseases, 8, 113-119.

[11] Falagas, M.E., Tansarli, G.S., Karageorgopoulos, D.E. and Vardakas, K.Z. (2014) Deaths Attributable to Carbapenem-Resistant Enterobacteriaceae Infections. Emerging Infectious Diseases, 20, 1170-1175. https://doi.org/10.3201/eid2007.121004

[12] Betbeu, A.C., Kamga, H.G., Toukam, M., Mbakop, C.D., Lyonga, E.E., Bilong, S. and Koulla-Shiro, S. (2015) Phenotypic Detection of Extended Spectrum Beta-Lactamase and Carbapenemases Produced by Klebsiella spp Isolated from Three Referrals Hospitals in Yaounde, Cameroon. British Microbiology Research Journal, 9, 1-9. https://doi.org/10.9734/BMRJ/2015/18250

[13] Yusuf, I., Haruna, M., Hamid, K.M., Muhammad, B. and Jega, S.A. (2011) Detection of AmpC, Carbapenemase and Extended Spectrum Beta Lactamases among Clinical Bacterial Pathogens in Nigeria. Africa Journal of Science, Technology and Social Sciences, 1, 8-24.

[14] Ebongue, C.O., Tsiazok, M.D., Mefo'O, J.P.N., Ngaba, G.P., Beyiha, G. and Adiogo, D. (2015) Evolution de la résistance aux antibiotiques des entérobactéries isolées à l'Hôpital Général de Douala de 2005 à 2012. The Pan African Medical Journal, 20, Article ID: 227. 
[15] Vaux, S., Carbonne, A., Thiolet, J. M., Jarlier, V., Coignard, B. and Raisin, C. (2011) Emergence of Carbapenemase-Producing Enterobacteriaceae in France, 2004 to 2011. Eurosurveillance, 16, Article ID: 19880. https://doi.org/10.2807/ese.16.22.19880-en

[16] Abbas, M., Cherkaoui, A., Fankhauser, C., Schrenzel, J. and Harbarth, S.J. (2012) Carbapénémases: implications cliniques et épidémiologiques pour la Suisse. Revue Médicale Suisse, 8, 882-884.

[17] Berrazeg, M., Diene, S.M., Medjahed, L., Parola, P., Drissi, M., Raoult, D. and Rolain, J.M. (2014) New Delhi Metallo-Beta-Lactamase around the World: An eReview Using Google Maps. Eurosurveillance, 19, Article ID: 20809. https://doi.org/10.2807/1560-7917.ES2014.19.20.20809

[18] Dortet, L., Poirel, L., Anguel, N. and Nordmann, P. (2012) New Delhi Metallo- $\beta$-Lactamase 4-Producing Escherichia Coli in Cameroon. Emerging Infectious Diseases, 18, 1540-1541. https://doi.org/10.3201/eid1809.120011

[19] Munoz-Price, L.S., Poirel, L., Bonomo, R.A., Schwaber, M.J., Daikos, G.L., Cormican, M., et al. (2013) Clinical Epidemiology of the Global Expansion of Klebsiella pneumoniae Carbapenemases. The Lancet Infectious Diseases, 13, 785-796. https://doi.org/10.1016/S1473-3099(13)70190-7

[20] Poirel, L., Naas, T. and Nordmann, P. (2010) Diversity, Epidemiology, and Genetics of Class D $\beta$-Lactamases. Antimicrobial Agents and Chemotherapy, 54, 24-38.

[21] Girlich, D., Bouihat, N., Poirel, L., Benouda, A. and Nordmann, P. (2014) High Rate of Faecal Carriage of Extended-Spectrum $\beta$-Lactamase and OXA-48 Carbapenemase-Producing Enterobacteriaceae at a University Hospital in Morocco. Clinical Microbiology and Infection, 20, 350-354. https://doi.org/10.1111/1469-0691.12325

[22] Sawa, T., Kooguchi, K. and Moriyama, K. (2020) Molecular Diversity of Extended-Spectrum $\beta$-Lactamases and Carbapenemases, and Antimicrobial Resistance. Journal of Intensive Care, 8, Article No. 13. https://doi.org/10.1186/s40560-020-0429-6

[23] Harchay, C., Battikh, H. and Fendri, C. (2016) Clonal Dissemination of a Multidrug-Resistant Strain of Klebsiella pneumoniae Producing OXA-48 Carbapenemase at a Tunisian Hospital. International Journal of New Technology and Research, 2, 21-27.

[24] Fournier, S. (2014) Maîtrise des bactéries hautement résistantes aux antibiotiques émergentes (BHRe). Journal des Anti-infectieux, 16, 80-88. https://doi.org/10.1016/j.antinf.2014.03.003

[25] Sağıroğlu, P., Hasdemir, U., Gelmez, G.A., Aksu, B., Karatuna, O. and Söyletir, G. (2018) Performance of "RESIST-3 O.K.N. K-SeT" Immunochromatographic Assay for the Detection of OXA-48 Like, KPC, and NDM Carbapenemases in Klebsiella pneumoniae in Turkey. Brazilian Journal of Microbiology, 49, 885-890. https://doi.org/10.1016/j.bjm.2018.02.002

[26] Han, R., Guo, Y., Peng, M., Shi, Q., Wu, S., Yang, Y., et al. (2021) Evaluation of the Immunochromatographic NG-Test Carba 5, RESIST-5 OOKNV, and IMP $K$-SeT for Rapid Detection of KPC-, NDM-, IMP-, VIM-Type, and OXA-48-Like Carbapenemase among Enterobacterales. Frontiers in Microbiology, 11, Article ID: 609856. https://doi.org/10.3389/fmicb.2020.609856 